\title{
Guidelines for the diagnosis and treatment of cholangiocarcinoma: an update
}

\author{
Shahid A Khan, ${ }^{1}$ Brian R Davidson, ${ }^{2}$ Robert D Goldin, ${ }^{3}$ Nigel Heaton, ${ }^{4}$ John Karani, ${ }^{4}$ \\ Stephen P Pereira, ${ }^{5}$ William M C Rosenberg, ${ }^{5}$ Paul Tait, ${ }^{6}$ Simon D Taylor-Robinson, ${ }^{1}$ \\ Andrew V Thillainayagam, ${ }^{1}$ Howard C Thomas, ${ }^{1}$ Harpreet Wasan ${ }^{7}$
}

\begin{abstract}
${ }^{1}$ Department of Hepatology and Gastroenterology Section, Imperial College London, London, UK

${ }^{2}$ Department of Hepatobiliary Surgery, Division of Medicine, University College London, London, UK

${ }^{3}$ Department of Medicine and Department of Histopathology, Imperial College London,

London, UK

${ }^{4}$ Department of Hepatobiliary and Pancreatic Surgery, King's College Hospital, London, UK ${ }^{5}$ UCL Institute of Liver and Digestive Health, Division of Medicine, University College London, London, UK ${ }^{6}$ Department of Radiology, Imperial College London, London, UK

${ }^{7}$ Department of Oncology, Imperial College London Hammersmith Hospital Campus, London, UK
\end{abstract}

\section{Correspondence to} Dr Shahid A Khan, Division of Medicine, Imperial College London, Liver Unit, 10th Floor, OEOM Wing, St Mary's Hospital Campus, South Wharf Road, London W2 1NY, UK and Department of

Gastroenterology, 3rd Floor, Hammersmith House, Hammersmith Hospital Campus, Du Cane Road, London W12 OHS, UK:

shahid.khan@imperial.ac.uk

Revised 10 July 2012 Accepted 13 July 2012

Published Online First 15 August 2012

\section{ABSTRACT}

The British Society of Gastroenterology guidelines on the management of cholangiocarcinoma were originally published in 2002. This is the first update since then and is based on a comprehensive review of the recent literature, including data from randomised controlled trials, systematic reviews, meta-analyses, cohort, prospective and retrospective studies.

\section{BACKGROUND \\ Development of guidelines}

These guidelines on the management of cholangiocarcinoma (CC) were originally published in 2002. ${ }^{1}$ This is the first update since and is based on a comprehensive review of the recent literature. The recent European HepatoPancreatoBiliary Association Consensus Conference on Cholangiocarcinoma guidelines have also been used as a source. ${ }^{2}$ Specific recommendations have been graded based on the quality of evidence available. In the absence of significant data, evidence was based on expert opinion. This manuscript has been developed with the support of The British Liver Trust and the UK cholangiocarcinoma charity, the Alan Morement Memorial Fund.

\section{Intent}

These guidelines are intended to bring consistency and improvement in the management from first suspicion of CC through to diagnosis and subsequent treatment. As stated in other British Society of Gastroenterology guidelines, patient preferences must be sought and decisions made jointly by the patient and health professional, based on the risks and benefits of any intervention. A multidisciplinary team approach is recommended, and these often complex cases should be managed in specialist centres with the relevant experience. The guidelines should not necessarily be regarded as the standard of care for all patients. Each case must be managed on the basis of individual clinical data.

\section{Levels of evidence}

Studies used as a basis for these guidelines are graded according to the quality of evidence using the Oxford Centre for Evidence-based Medicine levels of evidence (table 1). ${ }^{3}$ Grading of recommendations is as follows:

A: consistent level 1 studies.

B: consistent level 2 or 3 studies or extrapolations from level 1 studies.
C: level 4 studies or extrapolations from level 2 or 3 studies.

D: level 5 evidence or inconsistent or inconclusive studies of any level.

\section{EPIDEMIOLOGY}

$\mathrm{CC}$ is the second commonest primary liver tumour worldwide, after hepatocellular carcinoma (HCC). ${ }^{1}{ }^{2} 4{ }^{4}$ Incidence and mortality rates for intrahepatic CC have risen steeply and steadily across the world over the past few decades with concomitant falls in extrahepatic CC rates. ${ }^{4-14}$ Since the mid-1990s, more deaths have been coded in England and Wales due to CC than to HCC. ${ }^{45}$ CC kills approximately 1500 people annually in the UK, with approximately equal numbers of men and women. ${ }^{12}$ The cause of the rise in CC is unknown and is not explained by improvements in diagnosis. ${ }^{612-15}$ There is debate as to whether the rise in intrahepatic CC represents a genuine increase in true parenchymal primary CC. Recent evidence from USA and UK data suggest that rising intrahepatic CC rates partly reflects misclassification of perihilar ('Klatskin') tumours being incorrectly coded as intrahepatic instead of extrahepatic. ${ }^{12}$ The overall incidence and mortality from all CC, however, does appear to be increasing. ${ }^{12}$

\section{Risk factors}

\section{Established risk factors}

There are several established risk factors for CC, but these account for $<30 \%$ of all cases. ${ }^{15-19}$ Most cases of CC are sporadic. Primary sclerosing cholangitis (PSC), with or without ulcerative colitis, is the commonest known predisposing factor for $\mathrm{CC}$ in the Western world (lifetime risk $5-35 \%) .{ }^{18}$ In a study of 211 patients with PSC of whom $60 \%$ had inflammatory bowel disease (IBD), malignancies were the most frequent cause of death (44\%); $;^{18} 41 \%$ of patients developed colorectal cancer (CRC) and 15 (39\%) developed CC. Other malignancies included gall bladder cancer $(\mathrm{GBC}, \mathrm{n}=2)$, pancreatic cancer $(n=1)$, lymphoma $(n=3)$, melanoma $(n=1)$ and gastric cancer $(n=1)$. Median interval between PSC diagnosis and CC was 2.5 years (range $0-9.8$ years). The estimated risk of CC after 10 years was $9 \%$ with no significant differences in patients with and without IBD. ${ }^{18}$ In patients with IBD the 10 - and 20year risks for CRC were 14\% and 31\%, respectively, significantly higher than for non-IBD patients $(2 \%$ and $2 \%$ ). CC, cholangitis and age at entry were independent risk factors for the combined endpoint of death or liver transplantation. ${ }^{18}$ 
Table 1 Levels of evidence

\begin{tabular}{|c|c|c|c|c|}
\hline Level & Therapy/prevention, aetiology/harm & Prognosis & Diagnosis & DDX/symptom prevalence study \\
\hline 1a & $\begin{array}{l}\text { SR (with homogeneity*) of } \\
\text { randomised controlled trial (RCT) }\end{array}$ & $\begin{array}{l}\text { SR (with homogeneity*) of inception } \\
\text { cohort studies; CDR } \dagger \text { validated in } \\
\text { different populations }\end{array}$ & $\begin{array}{l}\text { SR (with homogeneity*) of Level } 1 \\
\text { diagnostic studies; CDR† with } 1 \mathrm{~b} \\
\text { studies from different clinical centres }\end{array}$ & $\begin{array}{l}\text { SR (with homogeneity*) of } \\
\text { prospective cohort studies }\end{array}$ \\
\hline 1c & All or none $e^{* *}$ & All or none case-series & Absolute SpPins and SnNouts†† & All or none case-series \\
\hline $2 b$ & $\begin{array}{l}\text { Individual cohort study (including } \\
\text { low-quality RCT; eg, <80\% } \\
\text { follow-up) }\end{array}$ & $\begin{array}{l}\text { Retrospective cohort study or follow-up } \\
\text { of untreated control patients in an RCT; } \\
\text { derivation of CDR } † \text { or validated on } \\
\text { split-sample } \ddagger \ddagger \text { only }\end{array}$ & $\begin{array}{l}\text { Exploratory } \ddagger \text { cohort study with good§ } \\
\text { reference standards; CDR† after } \\
\text { derivation, or validated only on } \\
\text { split-sample } \ddagger \text { or databases }\end{array}$ & $\begin{array}{l}\text { Retrospective cohort study, or } \\
\text { poor follow-up }\end{array}$ \\
\hline 2c & $\begin{array}{l}\text { 'Outcomes' research; ecological } \\
\text { studies }\end{array}$ & 'Outcomes' research & & Ecological studies \\
\hline 4 & $\begin{array}{l}\text { Case series (and poor quality } \\
\text { cohort and case-control } \\
\text { studies§§) }\end{array}$ & $\begin{array}{l}\text { Case series (and poor quality prognostic } \\
\text { cohort studies } \uparrow \uparrow \text { ) }\end{array}$ & $\begin{array}{l}\text { Case-control study, poor or } \\
\text { non-independent reference standard }\end{array}$ & $\begin{array}{l}\text { Case series or superseded } \\
\text { reference standards }\end{array}$ \\
\hline 5 & $\begin{array}{l}\text { Expert opinion without explicit } \\
\text { critical appraisal or based on } \\
\text { physiology, bench research or } \\
\text { 'first principles' }\end{array}$ & $\begin{array}{l}\text { Expert opinion without explicit critical } \\
\text { appraisal or based on physiology, } \\
\text { bench research or 'first principles' }\end{array}$ & $\begin{array}{l}\text { Expert opinion without explicit } \\
\text { critical appraisal or based on } \\
\text { physiology, bench research or } \\
\text { 'first principles' }\end{array}$ & $\begin{array}{l}\text { Expert opinion without explicit } \\
\text { critical appraisal or based on } \\
\text { physiology, bench research or } \\
\text { 'first principles' }\end{array}$ \\
\hline
\end{tabular}

*Homogeneity means a systematic review (SR) that is free of worrisome variations (heterogeneity) in the directions and degrees of results between individual studies. Not all SRs with statistically significant heterogeneity need be worrisome, and not all worrisome heterogeneity need be statistically significant.

†CDR, Clinical Decision Rule (algorithms or scoring systems which lead to a prognostic estimation or a diagnostic category).

$\neq$ Validating studies test the quality of a specific diagnostic test based on prior evidence. An exploratory study collects information and trawls the data (eg, using a regression analysis) to find which factors are 'significant'.

$\S$ Good reference standards are independent of the test, and applied blindly or objectively to applied to all patients. Poor reference standards are haphazardly applied, but still independent of the test. Use of a non-independent reference standard (where the 'test' is included in the 'reference', or where the 'testing' affects the 'reference') implies a level 4 study.

GGood follow-up in a differential diagnosis study is $>80 \%$, with adequate time for alternative diagnoses to emerge (eg, $1-6$ months acute, $1-5$ years chronic).

** Met when all patients died before the treatment became available but some now survive on it; or when some patients died before the treatment became available but none now die on it.

††An 'Absolute SpPin': a diagnostic finding whose Specificity is so high that a Positive result rules in the diagnosis. An 'Absolute SnNout': a diagnostic finding whose Sensitivity is so high that a Negative result rules out the diagnosis.

$\ddagger \mp$ Split-sample validation is achieved by collecting all the information in a single tranche, then artificially dividing this into 'derivation' and 'validation' samples.

$\S \S$ Poor quality cohort study: one that failed to clearly define comparison groups and/or failed to measure exposures and outcomes in the same (preferably blinded) objective way in both exposed and non-exposed individuals and/or failed to identify or appropriately control known confounders and/or failed to carry out a sufficiently long and complete follow-up of patients. Poor quality case-control study: one that failed to clearly define comparison groups and/or failed to measure exposures and outcomes in the same (preferably blinded) objective way in both cases and controls and/or failed to identify or appropriately control known confounders.

9 $\$$ Poor quality prognostic cohort study: one in which sampling was biased in favour of patients who already had the target outcome, or the measurement of outcomes was accomplished in $<80 \%$ of study patients, or outcomes were determined in an unblinded non-objective way, or there was no correction for confounding factors.

Other established risk factors for CC are summarised in table $2 .^{13-19}$

\section{Likely risk factors}

Less established but likely risk factors for CC include cirrhosis of any cause and chronic viral hepatitis B or C. ${ }^{19}$ A combination of recent cohort, population-based, case-control and observational studies from around the world suggest that obesity, diabetes, fatty liver disease, alcohol, smoking, IBD without PSC and polymorphisms of genes coding for carcinogen metabolism, DNA repair, inflammation and biliary transporters may also be risk factors. ${ }^{15-19}$ Toxins other than Thorotrast have been linked to CC, including dioxins, nitrosamines and vinyl chloride. ${ }^{16}$

\section{Anatomical classification}

The term 'cholangiocarcinoma' includes all bile duct cancers (intrahepatic, perihilar and distal extrahepatic). ${ }^{12} 2021 \mathrm{Up}$ to $20 \%$ of all CC are intrahepatic, according to published series,

Table 2 Established risk factors for cholangiocarcinoma (CC)

\begin{tabular}{|c|c|}
\hline Risk factor & References and details \\
\hline Age & $65 \%$ of patients aged $>65$ years $^{17} 19$ \\
\hline Chronic intraductal gallstones & \multirow{2}{*}{$\begin{array}{l}\text { Particularly in Asia where up to } 10 \% \text { of patients with hepatolithiasis (oriental cholangiohepatitis) develop intrahepatic } \\
\text { CC }^{17} 19151719\end{array}$} \\
\hline Bile duct adenoma and biliary papillomatosis & \\
\hline $\begin{array}{l}\text { Choledochal (bile duct) cysts and Caroli's } \\
\text { disease (intrahepatic biliary cysts) }\end{array}$ & $\begin{array}{l}\text { Lifetime risk of CC of } 6-30 \% \text {; risk of CC increases with age, and the average age of CC detection is in the fourth decade, } \\
\text { younger than sporadic } \mathrm{CC}^{15} 19\end{array}$ \\
\hline Thorotrast & Radiological agent is no longer licensed for use, although risk of CC induced by Thorotrast lasts several decades ${ }^{1516}$ \\
\hline $\begin{array}{l}\text { Liver flukes (Opisthorcis viverrini and } \\
\text { Clonorchis sinensis) }\end{array}$ & South-east Asia such as north-east Thailand where CC is relatively common ${ }^{13} 19$ \\
\hline Chronic typhoid carriage & South-east Asia; sixfold increased risk of all hepatobiliary malignancy ${ }^{13} 19$ \\
\hline
\end{tabular}


whereas $50-60 \%$ are perihilar, involving the bifurcation of the ducts. Perihilar CC are a subset of extrahepatic CC. ${ }^{12}$ Up to $20 \%$ of CC are distal extrahepatic tumours and $5 \%$ of tumours are multifocal. Given the differences in their frequency, pathobiology and management, intrahepatic, perihilar and distal extrahepatic CC should be viewed as separate entities. ${ }^{12} 17$

The extent of perihilar CC may be described by the Bismuth-Corlette classification (figure 1) ${ }^{20}$ :

- Type I: below confluence of left and right hepatic ducts.

- Type II: reaching confluence but not involving left or right hepatic ducts.

- Type III: occluding common hepatic duct and either right (IIIa) or left (IIIb) hepatic duct.

- Type IV: multicentric or bilateral intrahepatic segmental involvement; or involving confluence and both right and left hepatic ducts.

This classification is commonly used but has limitations. It does not take into account vascular encasement and distant metastases. A novel system for reporting perihilar CC was recently proposed based on tumour size, extent of disease in the main bile ducts, involvement of the hepatic artery and/or portal vein, lymph node involvement, distant metastases, volume of the putative remnant liver after resection and underlying liver disease. ${ }^{21}$ Although more complex than the Bismuth-Corlette classification, the important aim of this system is to standardise the prospective reporting of perihilar CC and help identify factors relevant to the outcome across multiple centres.

\section{PATHOLOGY}

\section{Histological classifications}

There are separate histological classifications of intrahepatic and extrahepatic CC. ${ }^{22-26}$ The WHO classifications are given in table 3.

\section{Macroscopic features of intrahepatic CC}

Intrahepatic CCs are whiter and firmer than HCCs as they contain more desmoplastic stroma. They occur more commonly in non-cirrhotic livers than HCCs and are divided into four macroscopic types (table 4). The intraductal type carries the best prognosis and the periductal type carries the worst.

\section{Histological grade}

Over $90 \%$ of CCs are adenocarcinomas and are classified (1-4) according to the percentage of tumour composed of glandular tissue. Some types of adenocarcinoma are not graded (eg, carcinoma in situ, clear cell adenocarcinoma and papillary adenocarcinoma). Signet ring cell carcinoma is graded as 3 and small cell carcinoma as 4 . Although histological grade correlates with postoperative outcome, stage is more important. ${ }^{23-26}$

\section{Molecular diagnosis}

CC is often associated with inactivation of tumour suppressor genes, for example, p53, Smad-4, bcl-2 and p16. ${ }^{15}$ 27-33 Mutations in oncogenes have also been described including K-ras, p53, c-erbB-2 and c-neu. Chromosomal aneuploidy has been reported in over $80 \%$ of PSC-associated CC. Although mutations can lead to detectable phenotypic changes, molecular profiling in biliary cytology does not currently have an established diagnostic or prognostic role. ${ }^{1527-33}$

\section{Combined hepatocellular-cholangiocarcinomas}

This entity should be distinguished from 'collision' tumours in which separate CCs and HCCs are present in the same liver. Combined hepatocellular-CCs are uncommon primary liver tumours accounting for $1-15 \%$ of all CCs. These are divided into classical and stem cell types. The latter is divided into the typical subtype in which there are nests of mature-appearing hepatocytes with peripheral clusters of small cells with the immunohistochemical profile of stem/progenitor cells; the intermediate cell subtype with tumour cells intermediate between hepatocytes and cholangiocytes; and the cholangiocellular type with tumour cells growing in an anastomosing pattern. In one series, $28 \%$ of HCCs contained cells expressing biliary/progenitor cell markers cytokeratin (CK) 7 and/or CK19. ${ }^{34}$ 'Non-classical' intrahepatic CCs are usually smaller and often arise in chronic liver disease, mostly HCV infection, and/or with significant fibrosis. ${ }^{35}$

\section{Distinction from other tumours}

Distinguishing intrahepatic CC from metastatic adenocarcinoma and other primary liver tumours can be difficult. Accurate differentiation, particularly from foregut metastases (lung, oesophagus, stomach, pancreas), often cannot be made histologically. Other modalities, especially imaging, are essential. Immunohistochemistry panels including CK7, CK19, CK20, CDX-2, TTF-1, oestrogen/progesterone receptors and PSA, depending on clinical context, can be helpful. ${ }^{35} \mathrm{CCs}$ are usually CK7 positive and CK20 negative. In distinguishing HCC from CC, lack of mucin production and expression of HepPar-1, CD10 and glypican- 3 by HCC are useful. ${ }^{35}$
Figure 1 Bismuth-Corlette classification of biliary strictures.

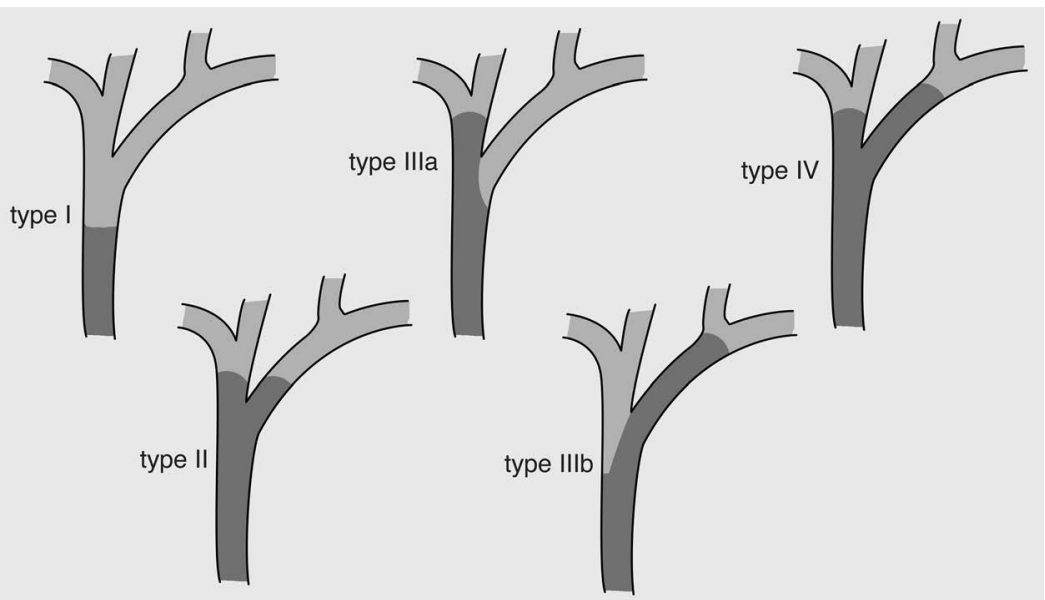


Table 3 WHO classification of biliary malignancies ${ }^{22-26}$

\begin{tabular}{|c|c|c|c|}
\hline Benign & Premalignant & & Malignant \\
\hline \multicolumn{4}{|l|}{ Tumours of intrahepatic bile ducts } \\
\hline Bile duct adenoma & \multicolumn{2}{|c|}{ Biliary intraepithelial neoplasia } & Intrahepatic cholangiocarcinoma \\
\hline Microcystic adenoma & \multicolumn{2}{|c|}{ Intraductal papillary neoplasm } & Intraductal papillary neoplasm with associated invasive neoplasia \\
\hline Biliary adenofibroma & \multicolumn{2}{|c|}{ Mucinous cystic neoplasm } & Mucinous cystic neoplasm with associated invasive neoplasia \\
\hline \multicolumn{2}{|l|}{ Premalignant } & \multicolumn{2}{|c|}{ Carcinoma } \\
\hline \multicolumn{4}{|l|}{ Tumours of extrahepatic bile ducts } \\
\hline \multicolumn{2}{|l|}{ Adenoma } & \multicolumn{2}{|c|}{ Adenocarcinoma } \\
\hline \multicolumn{2}{|c|}{ Biliary intraepithelial neoplasia } & \multicolumn{2}{|c|}{ Adenosquamous carcinoma } \\
\hline \multicolumn{2}{|c|}{ Intracystic (gall bladder) or intraductal (bile duct) papillary neoplasm } & \multicolumn{2}{|c|}{ Intracystic (gall bladder) or intraductal (bile duct) papillary neoplasm + associated invasive neoplasia } \\
\hline \multirow[t]{3}{*}{ Mucinous cystic neoplasm } & & \multicolumn{2}{|c|}{ Mucinous cystic neoplasm with associated invasive neoplasia } \\
\hline & & \multicolumn{2}{|c|}{ Squamous cell carcinoma } \\
\hline & & \multicolumn{2}{|c|}{ Undifferentiated carcinoma } \\
\hline
\end{tabular}

\section{DIAGNOSIS}

\section{Clinical features}

Perihilar or extrahepatic CCs typically present with features of biliary obstruction (jaundice, pale stool, dark urine and pruritus). ${ }^{1}$ Cholangitis is unusual without prior biliary instrumentation. CC is usually advanced at presentation, particularly with more proximal intrahepatic and perihilar tumours obstructing one duct. These often present with systemic manifestations of malignancy including malaise, fatigue and weight loss. ${ }^{1536}$ Some cases are detected incidentally as a result of scans performed for other indications.

\section{Blood tests}

No blood tests are diagnostic for CC. Liver function tests often show an obstructive picture. ${ }^{1}$ Aminotransferases are frequently normal but may be markedly raised in acute obstruction or cholangitis. Prolonged biliary obstruction can cause a reduction in fat soluble vitamins and an increase in prothrombin time. In advanced disease, non-specific markers of malignancy such as albumin, erythrocyte sedimentation rate, C-reactive protein and haemoglobin may be altered. ${ }^{15} 36$

\section{Serum tumour markers}

Carbohydrate antigen (CA) 19-9 and CA-125 are the most used serum tumour markers. ${ }^{15}$ 36-40 Overall, their sensitivity and specificity are low and they are not helpful for monitoring disease progression. ${ }^{37-40}$ They may be useful in conjunction with other diagnostic modalities.

CA19-9 is elevated in up to $85 \%$ of patients with CC with a sensitivity of $40-70 \%$, specificity of $50-80 \%$ and positive predictive value (PPV) of $16-40 \%$, depending on cut-off values. $^{36-38}$ CA19-9 elevation frequently occurs in PSC and other causes of non-malignant obstructive jaundice, but persistently raised levels of CA19-9 after decompression suggest malignancy. ${ }^{37-40}$ CA19-9 does not discriminate between CC, pancreatic or gastric malignancy and may also be elevated in severe hepatic

Table 4 Main macroscopic types of cholangiocarcinoma (CC)

\begin{tabular}{ll}
\hline Mass-forming & $\begin{array}{l}\text { Most common and usually arising from the small intrahepatic } \\
\text { bile ducts. CC arising from the large intrahepatic bile ducts } \\
\text { may be of any kind }\end{array}$ \\
$\begin{array}{l}\text { Periductal-infiltrating } \\
\text { Intraductal growth }\end{array}$ & $\begin{array}{l}\text { Worst prognosis } \\
\text { Least common and represents malignant transformation of } \\
\text { an intraductal papillary neoplasmBest prognosis }\end{array}$ \\
Mixed & \\
\hline
\end{tabular}

injury from any cause. Furthermore, 10\% of individuals lack Lewis antigen and cannot produce CA19-9. ${ }^{36-38} 40$

CA-125 is detectable in up to $65 \%$ of patients with CC. ${ }^{38} 40$ In a chemotherapy trial setting, a raised baseline CA-125 was found to be prognostic for survival. ${ }^{37}$ CA-125 is often raised in parenchymal liver disease and may not be helpful in this context.

Novel potential tumour markers linked to CC include Mac2BP, matrix metalloproteinase-7, insulin-like growth factor 1, interleukin 6, trypsinogen and MUCIN-5AC. None has yet been validated in large clinical studies.

\section{Immunoglobulin G4 (IgG4) cholangiopathy}

Immunoglobulin (Ig) G4-associated cholangiopathy, the biliary presentation of a multisystem inflammatory disorder in which affected organs have a lymphoplasmacytic infiltrate rich in IgG4-positive cells, can mimic CC. ${ }^{41}$ A review of 53 such cases reported that most were men $(85 \%)$, presented with obstructive jaundice $(77 \%)$, were associated with autoimmune pancreatitis (92\%), increased serum IgG4 levels (74\%) and abundant IgG4positive cells in bile duct biopsy specimens (88\%). ${ }^{41}$ Strictures were confined to intrapancreatic bile ducts in $51 \%$ of cases, and proximal extrahepatic/intrahepatic ducts were involved in $49 \%$. Following successful steroid therapy, relapse occurred in $53 \%$ of cases after steroid withdrawal. The presence of proximal extrahepatic/intrahepatic strictures was predictive of relapse. Steroid therapy normalised liver biochemistry in 61\% and biliary stents were safely removed in 17 of 18 patients. ${ }^{41}$ IgG4 cholangiopathy should be excluded in suspected cases of CC by testing for increased IgG4 in serum and biliary samples.

\section{Recommendations}

Diagnosis of CC should not rely solely on serum tumour marker measurements (Grade B).

- CA 19-9 remains the most widely used serum tumour marker for suspected CC, but does not exhibit high accuracy. It should be measured after biliary obstruction has been relieved (Grade B).

- IgG4 cholangiopathy should be excluded in suspected cases of CC (Grade B).

\section{Imaging}

Imaging is the main diagnostic modality for CC. ${ }^{42-55}$ Appearances include an intrahepatic mass lesion with characteristics of 
a metastasis, a hilar stricture or distal bile duct obstruction, with or without a discernible mass. Differentiating between benign and malignant biliary strictures is challenging.

\section{Ultrasonography}

CC should be suspected when there is biliary ductal dilation, particularly with a related mass lesion and consistent clinical history. In suspected biliary obstruction, ultrasonography (US) is reliable for excluding gallstones but is operator-dependent and is insufficient alone for investigating suspected CC. For detecting advanced CC in patients with PSC, US offers specificity and negative predictive value of $90 \%$, but sensitivity and PPV are only $50 \%{ }^{42-44}$ US may miss small tumours and cannot accurately define tumour extent. ${ }^{42-45}$ Colour-Doppler US may also detect tumour-induced compression or vascular thrombosis.

\section{High resolution/spiral CT}

Contrast CT has higher sensitivity for CC detection than US (up to $80 \%$ ), providing good views of intrahepatic mass lesions, dilated intrahepatic ducts, localised lymphadenopathy and extrahepatic metastases. However, the extent of CC is often not well-defined. ${ }^{42-45}$ Abdominal lymphadenopathy is common in PSC and does not necessarily indicate metastatic disease.

\section{MRI}

Contrast MRI is the optimal imaging investigation for suspected CC. ${ }^{45-48}$ In addition to avoiding radiation, MRI delineates hepatobiliary anatomy, local extent of duct involvement by MR cholangiopancreatography (MRCP), parenchymal abnormalities including the presence of liver metastases and hilar vascular involvement ( $\mathrm{MR}$ angiography). However, MRI is inferior to $\mathrm{CT}$ for detecting distant metastases, particularly in the lungs and bone. $^{4546}$

\section{Cholangiography (MRCP, ERCP, PTC)}

Cholangiography is essential for assessing the extent of bile duct involvement and resectability. ${ }^{14749} \mathrm{MRCP}$ is non-invasive, thus avoiding risks of endoscopic retrograde cholangiopancreatography (ERCP) or percutaneous transhepatic cholangiography (PTC) and avoiding radiation. ${ }^{46-48}$ In a retrospective study, MRCP had superior sensitivity (96\%), specificity (85\%) and accuracy (91\%) compared with ERCP (80\%, 75\% and 78\%, respectively) for differentiating between $\mathrm{CC}$ and benign strictures. ${ }^{47}$ A UK study comparing MRCP with ERCP in biliary obstruction predominantly relating to gallstone disease found in favour of MRCP with respect to cost-saving and quality of life. ${ }^{48}$ Similar studies on malignant biliary disease are lacking. ERCP and PTC allow bile sampling for cytology and stent insertion for relief of biliary obstruction. There is no clear evidence that PTC should generally be favoured over ERCP on the basis of the level of obstruction. Although ERCP is usually preferred above PTC, experience of and facilities for PTC should be available in treating centres for cases where ERCP has failed.

\section{Histology and cytology}

Although positive histology and/or cytology findings are often difficult to obtain, they are essential for confirming a diagnosis of CC, particularly in patients not proceeding to resection, and for clinical trials. Tumours are usually adenocarcinomas and have prominent desmoplastic stroma. However, except in cases where there is co-existing biliary dysplasia, it may not be possible, even with immunohistochemistry, to differentiate between CC and metastatic tumour. Examples of this include intraductal papillary neoplasm with associated invasive neoplasia, and mucinous cystic neoplasm with associated invasive neoplasia. ${ }^{50} 51$

Standard cytology from brushings at ERCP/PTC is positive in $<50 \%$ of CC cases, hence negative cytology findings do not exclude malignancy. ${ }^{2} 15$ Combining cytology with biopsy increases the positive yield to 40-70\%. Applying fluorescence in situ hybridisation (FISH), which uses fluorescently-labelled DNA probes to detect aneuploidy in cells, reportedly confirmed cancer in $60 \%$ of patients in whom standard brush cytology was negative. ${ }^{50}$ A subsequent study confirmed the ability of FISH to improve the diagnostic accuracy in indeterminate biliary strictures, increasing the sensitivity of brush cytology from $21 \%$ to $58 \% .{ }^{56}$ Including the presence of $9 \mathrm{p} 21$ deletion increased the sensitivity to $89 \%$. The specificity of FISH was $97 \%$ compared with $100 \%$ for cytology. ${ }^{56}$

\section{Endoscopic ultrasound}

Endoscopic ultrasound (EUS) allows good views of the distal extrahepatic biliary tree, hilar lesions, gall bladder, regional lymph nodes and vasculature. EUS facilitates fine needle aspiration of distal lesions and nodes which can enhance the sensitivity and PPV of CC detection to nearly 100\%. However, the negative predictive value is low, which does not permit exclusion of malignancy following a negative biopsy. ${ }^{52}$ The potential risk of tumour seeding has led some centres around the world to advise against EUS fine needle aspiration in potentially resectable tumours. However, this is not the case in most centres. Rates of tumour seeding are unclear, being reported as between 1:10000 and 1:40000, although this may be an underestimate.

\section{Positron emission tomography (PET) and PET-CT}

In a study comparing CT plus $M R$ versus positron emission tomography (PET)-CT, PET-CT exhibited no advantage for CC diagnosis but did have higher accuracy for detecting regional lymph node and distant metastases. ${ }^{54}$ PET-CT may have a potential role in preoperative staging, but this needs validating. 5455

\section{Cholangioscopy}

Given the disappointing accuracy of current diagnostic techniques, interest in cholangioscopy has renewed following technical improvements in endoscopes. ${ }^{57}$ In a prospective multicentre study, transpapillary cholangioscopy increased the ability to distinguish benign from malignant strictures compared with ERCP alone, and facilitated targeted biopsy. ${ }^{58}$ Cholangioscopy may be useful in experienced centres and further data are awaited.

\section{Recommendations}

- Patients with suspected CC should have: - Combined MRI and MRCP (Grade B) - Contrast enhanced high resolution CT (Grade B).

- Invasive cholangiography should be reserved for histological diagnosis, or therapeutic decompression where there is cholangitis, or stent insertion in irresectable cases (Grade B).

- The above techniques are complementary and may all be necessary as part of a surgical assessment (Grade B).

- FISH may enhance the diagnostic sensitivity of cytology samples (Grade B). 


\section{Staging}

CC staging is based on the tumour-node-metastasis (TNM) system. The 7th edition of the TNM classification introduced a specific staging system for intrahepatic CC, separate from HCC, providing better prognostic information. ${ }^{22} 23$ The T category is based on the number of tumour nodules, vascular invasion and direct extension into extrahepatic tissues. Unlike HCC, tumour size is not considered important. A positive resection margin (non-R0 resection) is a very poor prognostic factor.

Although distant spread is late and uncommon in CC, comprehensive staging must be carried out to screen for metastatic disease. CT provides more accurate information for this purpose than MRI. At presentation, up to $50 \%$ of patients are lymph node-positive and 10-20\% have peritoneal involvement. Most centres consider a staging laparoscopy to exclude local metastatic disease in those considered resectable on imaging. Only approximately $50 \%$ of patients with perihilar CC who undergo laparotomy are ultimately suitable for curative resection. In a study of 175 patients with suspected perihilar CC who underwent staging laparoscopy during the past decade, the overall yield and accuracy of staging laparoscopy decreased compared with earlier reports, possibly due to improved imaging techniques during this time period. ${ }^{59}$ Further studies on the benefit of staging laparoscopy in suspected CC are warranted.

Metastatic adenocarcinoma mimicking CC may arise from several organs, particularly the pancreas, stomach, breast, lung and colon. CC is difficult to differentiate from metastatic adenocarcinoma, particularly if the pathological sample is obtained from outside the biliary tree. Thorough clinical assessment and other investigations are necessary to exclude a primary from elsewhere. ${ }^{1}$ The extent to which this is pursued will depend on the individual case. ${ }^{60}$

\section{Recommendations}

- Studies obtained for the initial diagnosis may also provide staging information. However, to rule out metastatic disease, contrast CT of the abdomen, chest and pelvis should be carried out on all patients, particularly if resection is being considered (Grade B).

\section{Recommendations}

- Confirmatory histology and/or cytology at ERCP, laparoscopy or laparotomy should be obtained if at all possible (Grade C).

- However, due to the risk of tumour seeding, surgical assessment of resectability should be established prior to EUS-guided or percutaneous biopsy attempted (Recommendation Grade B).

- Laparoscopy may be considered to detect occult metastatic disease (Grade B).

\section{Screening for CC in PSC}

No benefit in screening for CC in PSC has been proven and there is no robust screening test. Nevertheless, most experts agree that early detection of CC in PSC is important to identify cases amenable to curative surgery and to avoid inappropriate liver transplantation. ${ }^{61-66}$ As well as an increased risk of CC, patients with PSC are also at increased risk of HCC; colorectal, gastric and pancreatic cancers; and malignant gall bladder polyps. ${ }^{62} 6466$ Up to $50 \%$ of CCs are diagnosed within 2 years of PSC diagnosis and the subsequent risk of CC is approximately $1 \%$ per year. ${ }^{64-66}$ The severity of liver disease (Child-Pugh or Mayo score) does not appear to be a significant risk factor. Smoking, alcohol, duration of IBD if present, previous CRC/dysplasia and the HLA-DR4, DQ8 haplotype are reported risk factors for malignancy in PSC, but none has been validated as a predictive factor. A suggested algorithm for CC screening in PSC is given in figure 2. This is unproven and based on expert opinion. Regular investigations, including surveillance colonoscopies in patients with PSC and IBD and US for gall bladder lesions, are recommended in both the European Association for the Study of the Liver (EASL) and the American Association for the Study of Liver Diseases (AASLD) guidelines.

Role of ursodeoxycholic acid (UDCA)

Small retrospective studies have suggested that ursodeoxycholic acid (UDCA) may reduce the risk of colonic dysplasia and CRC in patients with PSC. No significant protective effect of UDCA on the risk of CC has been demonstrated. Recent guidelines from both EASL and AASLD have concluded that the role of UDCA in PSC is currently unclear and that high-dose UDCA may even be harmful. ${ }^{64-66}$

\section{TREATMENT}

\section{Surgery}

Surgery is the only curative treatment for patients with CC; however, fewer than one-third of patients are resectable at diagnosis. ${ }^{67-73}$ Five-year survival rates following resection of intrahepatic CC, distal extrahepatic CC and hilar tumours are $22-44 \%$, $27-37 \%$ and $11-41 \%$, respectively. ${ }^{67} 6871-73$ Survival depends on local clearance (R0 or R1 status), vascular invasion and lymph node metastases. R0 resection and well-differentiated tumour grading are independently associated with improved survival and lymph node involvement (occurring in $50 \%$ at presentation) is associated with reduced long-term survival. ${ }^{67} 687273$ Peritoneal and distant metastases (10-20\% at presentation) are contraindications to surgical resection. In a multivariate analysis, postresection prognosis correlated most strongly with clinical stage and multiplicity of lesions. ${ }^{73}$

\section{Resectable tumours}

Resection, which should be guided by medical risk rather than age, involves a major operative procedure and requires appropriate surgical and anaesthetic experience. Surgical treatment depends on the site and extent of bile duct involvement by tumour Intrahepatic CCs are usually treated by resection of the involved segments or lobe of the liver. Distal CCs are managed by pancreatoduodenectomy, as with ampullary or pancreatic head cancers. Major hepatectomy for hilar CCs carries a considerable risk of hepatic insufficiency if there is a small future liver remnant. Portal vein embolisation of the liver lobe to be removed is a safe method for increasing the future liver remnant and permits potentially curative hepatic resection to be carried out. ${ }^{74-76}$

\section{Liver transplantation for CC}

Historically, liver transplantation for CC was associated with rapid recurrence of disease and poor survival rates: around $10 \%$ for intrahepatic CC and 25\% for extrahepatic CC. ${ }^{77} 78$ Recent studies, however, have reported 5 -year survivals of over $70 \%$ in patients carefully selected by their response to pre-transplant 
Figure 2 Suggested algorithm for cholangiocarcinoma screening in primary sclerosing cholangitis

(Recommendation Grade D). AFP, alpha-fetoprotein; CC, cholangiocarcinoma; CRC, colorectal carcinoma; ERCP, endoscopic retrograde cholangiopancreatography; EUS, endoscopic ultrasound; FISH, fluorescence in situ hybridisation; FNA, fine-needle aspiration; IBD, inflammatory bowel disease; MDT, multidisciplinary team; MRCP, magnetic resonance cholangiopancreatography; PSC, primary sclerosing cholangitis; US, ultrasonography.

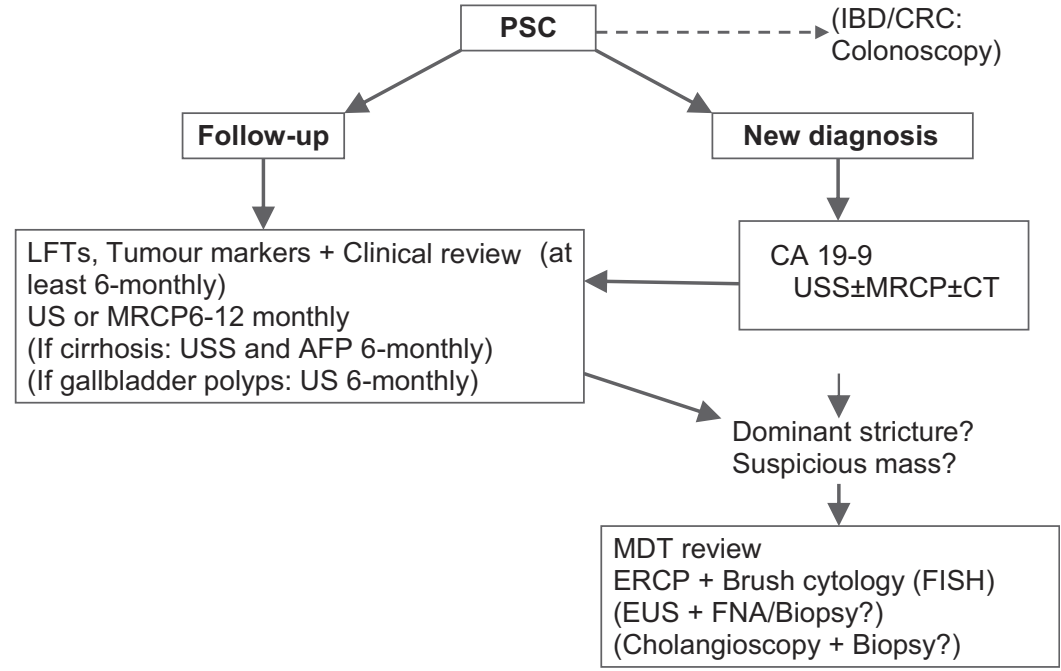

chemoradiation. $^{79} 80$ This applies to a minority of patients with $\mathrm{CC}$ and most of the published data so far have been from a single centre in the USA. However, a recent study analysed data from 12 transplant centres in the USA. Each had treated at least three patients with perihilar CC using varying protocols of neoadjuvant chemoradiation followed by liver transplantation between 1993 and 2010. Two hundred and eighty-seven patients were treated and 71 dropped out before transplantation. The overall intent-totreat survival rate was $53 \% 5$ years after treatment and the posttransplant recurrence-free survival rate was $65 \%$. Patients with tumour mass $>3 \mathrm{~cm}$, transperitoneal tumour biopsy, metastatic disease or with a prior malignancy had significantly shorter survival times. Although most patients $(n=193)$ came from one centre, the other 11 centres had similar survival times. ${ }^{81}$

\section{Recommendations}

- For perihilar CC, the Bismuth classification is a guide to the extent of surgery required (aim is tumour-free margin of $>5 \mathrm{~mm}$ ). Surgical treatment is principally as follows (Grade B):

- For types I and II: en bloc resection of the extrahepatic bile ducts and gall bladder, regional lymphadenectomy and Roux-en-Y hepaticojejunostomy.

- For type III: as above plus right or left hepatectomy.

- For type IV: not usually resectable but extended right or left hepatectomy may be feasible, dependent on biliary anatomy.

- Segment 1 of the liver may preferentially harbour metastatic disease from hilar CC and removal should be considered with stages II-IV.

- Intrahepatic CCs are managed by segmental or lobe resection.

- Distal CCs are treated by pancreato-duodenectomy.

- Increasing data suggest that liver transplantation for CC can be successful in rigorously selected patients undergoing neoadjuvant therapy in highly specialised centres.

\section{Adjuvant therapy for resectable tumours}

There is no current evidence to support the use of adjuvant chemotherapy or radiotherapy. Appropriate trials are needed to address this issue. The largest trial currently accruing is the BILCAP trial. ${ }^{82}$

\section{Palliative procedures} disease may be palliated by biliary stenting rather than a surgical bypass. Stent placement resulting in adequate biliary drainage improves survival. Surgical bypass has not been demonstrated to be superior to stenting. Close liaison between oncological, palliative care and surgical teams is essential.

\section{Reporting surgical specimens}

Surgical resection specimens should be reported systematically, for example, according to Royal College of Pathologists' guidelines. $^{26}$ The final report should include the following information:

\section{Tumour}

a. Histological type

b. Histological grade

c. Extent of invasion (according to the TNM system)

d. Blood/lymphatic vessel invasion

e. Perineural invasion: this is common and has prognostic significance.

\section{Margins}

These must be adequately sampled because local recurrence is related to involvement of the margins. This is particularly important because extrahepatic CC may be multifocal in up to $5 \%$ of cases.

\section{Regional lymph nodes}

To stage lymph nodes accurately, the node groups must be specifically identified. Peripancreatic nodes located along the body and tail of the pancreas are considered sites of distant metastasis.

\section{Additional pathological findings}

These must be noted if present (eg, carcinoma in situ, sclerosing cholangitis).

\section{Metastases}

Metastases to other organs or structures should be reported.

\section{Biliary decompression and stents}

\section{Stenting prior to surgery}

Preoperative biliary drainage is controversial. It has been associated with bacteriobilia and fungal colonisation, higher
Surgical resection with palliative rather than curative intent is unproven. Symptoms from biliary obstruction in irresectable 
rates of postoperative sepsis, wound infection, longer hospital stay and increased cost. ${ }^{83-90}$ A meta-analysis of preoperative biliary drainage for obstructive jaundice included four trials $(n=235)$ comparing PTC-biliary drainage with direct surgery and one trial $(n=85)$ comparing preoperative endoscopic drainage with direct surgery. ${ }^{91}$ Overall, there were no significant differences in mortality, morbidity or complications between the preoperative biliary drainage and the direct surgery groups. One of the included studies found that preoperative endoscopic biliary drainage prolonged hospital stay and increased cost. However, the overall strength of evidence was deemed low due to the poor quality of the included trials. ${ }^{91}$ A multicentre randomised trial comparing preoperative biliary drainage with surgery alone for patients with pancreatic cancer and obstructive jaundice included 206 patients; 106 were randomly assigned to undergo preoperative biliary drainage for 4-6 weeks (primarily by ERCP) followed by surgery, and 96 to surgery alone within 1 week of diagnosis. ${ }^{92}$ The rates of serious complications were $39 \%$ in the early surgery group and $74 \%$ in the biliary drainage group (RR in the early surgery group $0.54, \mathrm{p}<0.001)$. Mortality and the length of hospital stay did not differ between the groups. ${ }^{92}$ Although most of the data relate to obstructive jaundice from cancers other than $\mathrm{CC}$, on current evidence the routine use of preoperative biliary drainage cannot be recommended. In patients who are severely malnourished or have acute suppurative cholangitis and in those in whom major hepatic resection is planned, preoperative drainage may be beneficial. ${ }^{93}$ Rigorously designed randomised controlled trials (RCTs) with appropriate sample sizes are required with respect to CC.

\section{Recommendation}

Routine biliary drainage before assessing resectability or preoperatively should be avoided except for certain situations such as acute cholangitis, with modification of antibiotic prophylaxis according to patient characteristics and local microbiological specialist advice (Grade B).

\section{Stents for palliation of jaundice}

Most patients with CC have unresectable disease. In such patients, a study from the USA found that endoscopic stenting cost significantly less and was associated with longer survival than surgical treatment (19 vs 16.5 months), suggesting that endoscopic stenting is the procedure of choice for palliative biliary drainage. ${ }^{94}$ Most initially inserted stents are plastic. Stents of diameter $\geq 10$ Fr usually remain patent for approximately 3 months. Narrower stents have lower patency rates and should not be used routinely. Covered removable self-expanding metal stents (SEMS) may also be used and some specialists prefer SEMS in patients who are candidates for neoadjuvant therapies. ${ }^{95}$

Biliary drainage by the percutaneous route can be effective, particularly for high strictures involving segmental ducts. A multicentre retrospective Korean study of 85 patients with newly diagnosed advanced hilar CC who did not undergo surgery, chemotherapy or radiotherapy compared percutaneous versus endoscopic SEMS insertion. ${ }^{96}$ Successful biliary decompression was significantly higher in the percutaneous group than in the endoscopic group ( $93 \%$ vs $77 \%, p=0.049)$. Procedure- related complications, median survival and stent patency duration were similar in both groups. ${ }^{96}$

\section{Bilateral versus unilateral stents in hilar CC/advanced malignant} biliary strictures

Bilateral versus unilateral stent insertion for hilar strictures is controversial. Early small studies reported that 30-day mortality and cholangitis were lower in patients who underwent bilateral compared with unilateral drainage for hilar strictures. ${ }^{88} 899397$ Failure to drain opacified lobes is associated with a poorer outcome. Post-stent cholangitis can be reduced by minimising the amount of contrast injected. Careful imaging with MRCP to plan endoscopic stent placement in complex hilar tumours may guide optimum stent placement. In particular, non-atrophic areas of the liver with a likelihood of providing viable bile production should be considered for drainage. ${ }^{93}$ Bilateral stent insertion is technically challenging and should not be carried out routinely. If contemplated, it should be performed in expert centres.

\section{Metal versus plastic stents}

Most patients with malignant biliary obstruction treated by plastic stents will require at least one stent change. Metal stents have several advantages over plastic stents. ${ }^{98-102}$ They have a relatively narrow delivery system (8Fr) with a wider diameter on deployment $(10 \mathrm{~mm})$. SEMS are also available that are $8 \mathrm{~mm}$ on deployment, which may help in stent selection, depending on the patient's anatomy. The patency rates of metal stents are significantly greater than those of plastic stents (up to 12 months vs 3 months). Metal stents are associated with fewer ERCPs, a shorter hospital stay and fewer complications than plastic stents in patients who survive more than 6 months. A retrospective study of unresectable hilar CC in the USA found that SEMS were more cost-effective than plastic stents for palliative drainage. ${ }^{102}$ Other studies have also found that metal stents are more cost-effective in patients surviving more than 4 months. Plastic stents may be satisfactory for patients surviving less time than this.

Disadvantages of uncovered metal stents include being difficult to remove endoscopically and potentially making surgery more technically challenging. Metal stents should not be deployed for biliary strictures prior to a multidisciplinary team decision on resectability. Tumour growth through the mesh of metal stents may lead to further problems with biliary obstruction and sepsis. This may be overcome by inserting plastic stents through the lumen of the metal stent, or placement of a further mesh metal stent where technically possible.

\section{Covered versus uncovered stents}

Covered biliary metal stents have recently been developed to prevent tumour ingrowth. ${ }^{103-106}$ A prospective RCT comparing covered and uncovered stents in irresectable malignant distal biliary obstruction found no difference in survival but a longer time to obstruction in the group with covered stents, who overall had fewer interventions and lower costs. Patency was higher in pancreatic cancer and in lymphadenopathy-associated obstruction compared with biliary malignancy, but numbers of the latter were small. ${ }^{103}$ Another RCT demonstrated improved survival in patients with extrahepatic CC who percutaneously received a covered (243 days) compared with an uncovered stent (180 days), with comparable cost and complication rates. ${ }^{105}$ The incidence of stent dysfunction was significantly lower in the covered stent group. ${ }^{105}$ The largest study so far in this area was a multicentre unblinded RCT of 400 patients with irresectable 
distal malignant biliary obstruction. Patients were randomised to ERCP with insertion of a covered or uncovered metal (nitinol) stent. ${ }^{106}$ There were no significant differences in stent patency time, patient survival time or complication rates between covered and uncovered metal stents. However, covered stents migrated significantly more often than uncovered stents and tumour ingrowth was more frequent with uncovered stents. ${ }^{106}$

\section{Complications of stenting}

Complications of stents include complications of endoscopy and sedation. Following palliative stenting, patients can die from recurrent sepsis, biliary obstruction and stent occlusion, as well as disease progression. Acute cholecystitis from covered stents is another recognised complication.

\section{Photodynamic therapy}

In an early prospective open-label trial, 39 patients with unresectable CC were randomised to stenting alone or stenting and photodynamic therapy (PDT). ${ }^{107}$ The PDT group had a significantly higher median survival (493 days vs 98 days). ${ }^{107}$ PDT was further evaluated in the larger UK Photostent-02 trial in which 92 patients with histologically or cytologically confirmed biliary tract cancer (BTC) were randomised to receive either PDT plus stenting or stenting alone. ${ }^{108}$ Overall survival was 5.6 months for PDT plus stenting and 8.5 months for stenting alone (HR $1.8, \mathrm{p}=0.027)$. Nine patients $(20 \%)$ in the PDT/stenting arm and $19(41 \%)$ in the stenting alone arm received subsequent chemotherapy. Although overall survival was significantly improved among those who had chemotherapy compared with those who did not (11.1 vs 4.8 months, $p=0.001$ ), adjusting for this only reduced the PDT/stenting HR from 1.8 to 1.6, suggesting that failure to receive subsequent chemotherapy did not completely explain the excess risk from PDT. ${ }^{108}$

\section{Recommendations}

- Initial stent insertion for biliary obstruction should be plastic or covered SEMS, particularly if the diagnosis and resectability are undecided (Grade C).

- If the initial plastic stent becomes blocked, replacement with a metal stent is favoured if the estimated survival is expected to be $>4$ months (Grade B).

- Covered stents cannot be recommended for routine use based on current evidence (Grade B).

- Surgical bypass should be reconsidered in patients with a good estimated life expectancy where stenting has failed (Grade C).

- Photodynamic therapy cannot be recommended for routine use based on the most recent data (Grade A).

\section{Oncological approaches}

Given that most patients present with unresectable disease and at least half have lymph node metastases, oncological approaches could potentially have a beneficial impact on many patients. ${ }^{109-116}$ As a general guide from trial data, patients who are relatively fit and are not deteriorating rapidly should be treated early in the course of their disease rather than waiting for clinical progression. The performance status (PS) is a major prognostic factor. Patients should have a WHO or ECOG PS of 0 or 1 after optimisation of biliary drainage. Even achieving stable disease in patients on therapy correlates with length and quality of life. This is particularly important because of the frequent difficulty in confirming objective radiological responses, particularly in the perihilar area. Good symptom control is paramount and requires multidisciplinary team input and, for many patients, palliative care is immediately appropriate.

\section{Chemotherapy \\ Locally advanced or metastatic inoperable CC and GBC (Evidence level 1a)}

Until recently, chemotherapy for CC had poor results and studies were small and disparate. In 2010, a new standard of care in unresectable BTC was established with the reporting of the UK NCRI ABC-01 and ABC-02 trials. ${ }^{39} 113114$ ABC-02 is the largest randomised phase III study reported in BTC to date. Four hundred and ten patients with locally advanced or metastatic CC, or gall bladder or ampullary cancer were randomised to receive 24 weeks of either cisplatin plus gemcitabine (CisGem) or gemcitabine (Gem) alone. ${ }^{39}$ After a median follow-up of 8.2 months, the median overall survival was 11.7 months for the CisGem group $(n=204)$ and 8.1 months for the Gem group $(n=206)$, HR 0.64 (95\% CI 0.52 to $0.80, p<0.001)$. The median progression-free survival was 8.0 months for the CisGem group versus 5.0 months for the Gem group $(p<0.001)$. Patients in the CisGem group also had a significantly improved tumour control rate $(81.4 \%$ vs $71.8 \%, p=0.049)$. Overall toxicity was similar between the arms, with a slight excess in clinically non-significant haematological toxicities for the CisGem group. ${ }^{39}$ The small proportion of patients with PS 2 in this study did not gain a survival advantage. Similarly, there was no clear advantage for the small subset of patients with ampullary cancer. However, patients with GBC (about 30\% of the total cohort and wellbalanced between the arms) derived as much benefit as the patients with CC. The efficacy of CisGem has been validated in the Japanese equivalent of the ABC-02 study, which reported similar outcomes. ${ }^{114}$ An investigation in the USA comparing direct medical costs, patient time costs and quality-adjusted life years in BTC found CisGem treatment to be cost-effective compared with Gem monotherapy. ${ }^{115}$

There are encouraging reports of several patients being successfully downstaged with neoadjuvant chemotherapy and converted to operability in phase II studies, with occasional long-term survivors. Regimens combining chemotherapy with newer targeted biological agents are now being tested.

\section{Adjuvant therapy}

There is currently no evidence to support postoperative adjuvant therapy for CC outside a trial setting. A phase III RCT evaluated postoperative adjuvant therapy with mitomycin $\mathrm{C}$ and 5-fluorouracil versus surgery alone in resected pancreatobiliary carcinoma. ${ }^{116}$ A significant survival benefit for patients with GBC was found. However, the trial was underpowered to show a survival advantage in CC and there was no significant survival advantage for patients with BTC overall. The UK NCRI BILCAP study is currently accruing and compares postoperative capecitabine monotherapy with observation alone. The trial is expected to report in $2014 .^{82}$

\section{Radiotherapy}

\section{External beam radiotherapy and chemoradiation}

There is currently no evidence to support the routine use of radiotherapy postoperatively or for unresectable disease. Radiotherapy may have important palliative value-for example, for 
localised metastases or uncontrolled bleeding. ${ }^{109-112}$ The role of chemoradiation remains to be established in RCTs.

\section{Local radiation techniques: intraoperative or intraductal brachytherapy}

A small non-randomised retrospective study of metal stent insertion combined with external beam radiotherapy versus stent insertion alone showed a longer survival in the combination group (10.6 vs 6.4 months) and also longer stent patency (9.8 vs 3.7 months). ${ }^{109}$ However, overall patency rates were shorter than previously reported for metal stents. A large epidemiological retrospective study of $17 \%$ of 3839 patients with intrahepatic CC (on the USA SEER database) demonstrated a small survival benefit for radiotherapy plus surgery compared with radiotherapy alone (11 vs 7 months). ${ }^{110} \mathrm{~A}$ similar study in 4758 patients with extrahepatic CC suggested that palliative radiotherapy prolonged survival; however, the benefit associated with surgery and/or radiotherapy was not significant after controlling for potential confounders. ${ }^{111}$ In a small prospective randomised study of perihilar CC, 21 patients with percutaneous stenting followed by intraluminal Ir192 brachytherapy and external radiotherapy were compared with 21 patients with stenting only. The combination group had a significantly improved mean survival compared with the group with stenting alone (388 vs 298 days). ${ }^{112}$ The value of intraoperative radiotherapy or brachytherapy is unproven and has not been shown to be superior to standard chemotherapy, chemoradiation or stenting alone.

\section{Recurrent bile duct cancer}

The prognosis for any treated patient with progressing, recurring or relapsing bile duct cancer is poor. Further treatment depends on several factors including prior treatment, site of recurrence, specific symptoms and PS. Relief of recurrent jaundice usually improves quality of life. Clinical trials should be considered if appropriate.

\section{Locoregional therapies}

Recent literature suggests an emerging role for locoregional therapies in intrahepatic CC, including transcatheter arterial chemoembolisation, radiofrequency ablation and transarterial hepatic yttrium-90 ((90)Y) radioembolisation, which have previously been successfully used for the treatment of HCC and colorectal liver metastases. ${ }^{117-125}$

\section{Transcatheter arterial chemoembolisation (TACE)}

In a retrospective matched series of transcatheter arterial chemoembolization (TACE, $n=72$ ) versus supportive therapy alone $(n=83)$ for unresectable intrahepatic CC, survival was significantly improved in the TACE group (median 12.2 vs 3.3 months, $p<0.001$ ). Toxicities were significantly higher in the TACE group but no patients died within 30 days following TACE. ${ }^{117}$ In another retrospective analysis of 114 patients with intrahepatic CC who underwent curative resection, adjuvant TACE was given in 57 cases. In patients with poor prognostic factors (tumour size $>5 \mathrm{~cm}$, TNM stage III/IV), 3- and 5-year survival rates were $34 \%$ and $14 \%$ in the adjuvant TACE group compared with $0 \%$ and $0 \%$ in the non-TACE group, respectively $(p<0.001)$. TACE had no effect on survival in patients without poor prognostic factors. ${ }^{118}$

\section{Radiofrequency ablation}

Several recent small studies have suggested that percutaneous US-guided thermal ablation for unresectable intrahepatic CC is safe and potentially effective, particularly for primary and relatively smaller tumours. ${ }^{120-124}$ In a Chinese study, 18 patients (8 primary and 10 recurrent cases after resection) with 25 intrahepatic CC nodules underwent US-guided thermal ablation with curative intention. ${ }^{120}$ Complete ablation was achieved in $23(92 \%)$ nodules (diameter $0.7-4.3 \mathrm{~cm}$ ) and incomplete ablation was found in the remaining two tumours which were larger $(6-7 \mathrm{~cm})$. There were no treatment-associated deaths. Overall survival rates at 36 and 60 months were $30 \%$ and $30 \%$, respectively. The patient source (primary or recurrent case, $p=0.001$ ) and the number of nodules $(p=0.038)$ were significant prognostic factors for recurrence-free survival. Survival rates for primary intrahepatic CC at 36 and 60 months were $63 \%$ and $63 \%$, respectively. ${ }^{120}$

\section{Radioembolisation}

Radioembolisation using (90)Y microspheres was assessed in 33 patients with unresectable intrahepatic CC and appeared safe. ${ }^{125}$ Median overall survival was 22 months and time-to-progression (TTP) was 9.8 months. Survival and TTP were significantly prolonged in patients with ECOG 0 versus ECOG 1 or 2 (median overall survival 29.4, 10 and 5.1 months, respectively; TTP 17.5, 6.9 and 2.4 months, respectively). Tumour burden and tumour response were other predictors of survival $(p<0.001) .{ }^{125}$

The emerging data for locoregional therapies in unresectable CC are encouraging, but larger studies are required to determine their efficacy.

\section{Recommendations}

- Gemcitabine and Cisplatin combination chemotherapy is recommended for locally advanced or metastatic unresectable CC (Grade A).

- Further data on specific disease subsets such as perihilar CC are warranted to identify the best treatment combination options for different subcategories of CC (Grade B).

- All operable patients should be offered adjuvant treatment trials. Similarly, all patients who have inoperable tumours or who are operable but have not been rendered disease-free, or those patients with recurrences should be actively encouraged to participate in chemotherapy and/or radiotherapy clinical trials (Grade B).

- Patients with PS $\geq 2$ after adequate drainage and appropriate treatment of intercurrent sepsis should be considered for palliative care (Grade B).

- Locoregional therapies such as radioembolisation and TACE need prospective randomised data to assess their true value.

\section{REVISION OF GUIDELINES}

We recommend that these guidelines are regularly audited and we request feedback from all users. These guidelines should be revised in the light of new evidence that is likely to improve management.

Acknowledgements We are grateful for input and support from The British Liver Trust and the Alan Morement Memorial Fund.

Contributors SAK wrote the original draft of this manuscript and subsequently coordinated input from the co-authors, all of whom have contributed to the sections of 
the document relevant to their specialty and field(s) of interest, as well as the overall manuscript

Competing interests None.

Provenance and peer review Not commissioned; externally peer reviewed.

\section{REFERENCES}

1. Khan SA, Davidson BR, Goldin R, et al. UK guidelines for the diagnosis and treatment of cholangiocarcinoma. Gut 2002;51(Suppl 6):VI1-9.

2. European HPB Association Consensus Conference on Cholangiocarcinoma. HPB 2008;2:71-147

3. Phillips B, Ball C, Sackett D, et al. Oxford Centre for Evidence-based Medicine 2009. Updated by Howick J, 2009. http://www2.cch.org.tw/ebm/file/CEBM-Levelsof-Evidence.pdf

4. Taylor-Robinson SD, Toledano MB, Arora S, et al. Increase in mortality rates for intrahepatic cholangiocarcinoma in England and Wales 1968-1998. Gut 2001;48:816-20.

5. Khan SA, Taylor-Robinson SD, Toledano MB, et al. Changing international trends in mortality rates for liver, biliary and pancreatic tumours 1979-1997. J Hepatol 2002;37:806-13.

6. Shaib Y, El-Serag HB. The epidemiology of cholangiocarcinoma. Semin Liver Dis 2004;24:115-25.

7. Patel T. Increasing incidence and mortality of primary intrahepatic cholangiocarcinoma in the United States. Hepatology 2001;33:1353-7.

8. Patel T. Worldwide trends in mortality from biliary tract malignancies. BMC Cancer 2002;2:10.

9. West J, Wood H, Logan RF, et al. Trends in the incidence of primary liver and biliary tract cancers in England and Wales 1971-2001. Br J Cancer 2006:94:1751-8.

10. McGlynn KA, Tarone RE, El-Serag HB, et al. A comparison of trends in the incidence of hepatocellular carcinoma and intrahepatic cholangiocarcinoma in the United States. Cancer Epidemiol Biomarkers Prev 2006;15:1198-203.

11. Shaib YH, Davila JA, McGlynn KA, et al. Rising incidence of intrahepatic cholangiocarcinoma in the United States: a true increase? J Hepatol 2004 40:472-7.

12. Khan SA, Emadossadaty S, Ladep N, et al. Rising trends in cholangiocarcinoma: is the ICD classification system misleading us? J Hepatol 2012;56:848-54.

13. Khan SA, Toledano MB, Taylor-Robinson SD. Epidemiology, risk factors and pathogenesis of cholangiocarcinoma. HPB (Oxford) 2008:10:77-82.

14. Welzel TM, McGlynn KA, Hsing AW, et al. Impact of classification of hilar cholangiocarcinomas (Klatskin tumors) on the incidence of intra- and extrahepatic cholangiocarcinoma in the United States. J Natl Cancer Inst 2006;98:873-5.

15. Khan SA, Taylor-Robinson SD, Davidson BR, et al. Cholangiocarcinoma: seminar Lancet 2005; 366:1303-14

16. Adenugba A, Khan SA, Taylor-Robinson SD, et al. Polychlorinated biphenyls in bile of patients with biliary tract cancer. Chemosphere 2009;76:841-6.

17. Blechacz B, Komuta M, Roskams T, et al. Clinical diagnosis and staging of cholangiocarcinoma. Nat Rev Gastroenterol Hepatol 2011:8:512-22.

18. Claessen MM, Vleggaar FP, Tytgat KM, et al. High lifetime risk of cancer in primary sclerosing cholangitis. J Hepatol 2009;50:158-64.

19. Tyson GL, El-Serag HB. Risk factors for cholangiocarcinoma. Hepatology 2011;54:173-84

20. Bismuth H, Castaing D. Hepatobiliary Malignancy. London: Edward Arnold, 1994:416-24.

21. Deoliveira ML, Schulick RD, Nimura $Y$, et al. New staging system and a registry for perihilar cholangiocarcinoma. Hepatology 2011:53:1363-71.

22. Sobin LH, Gospodarowicz MK, Wittekind C, eds. TNM Classification of Malignant Tumours (UICC International Union Against Cancer). 7th edn. Wiley-Blackwell, 2009.

23. Edge SB, Compton CC. The American Joint Committee on Cancer: the 7th edition of the AJCC cancer staging manual and the future of TNM. Ann Surg Oncol 2010:17:1471-4.

24. Nathan H, Aloia TA, Vauthey JN, et al. A proposed staging system for intrahepatic cholangiocarcinoma. Ann Surg Oncol 2009;16:14-22.

25. Nakeeb A, Pitt HA, Sohn TA. Cholangiocarcinoma: a spectrum of intrahepatic, perihilar and distal tumors. Ann Surg 1996;224:463-75.

26. The Royal College of Pathologists. http://www.rcpath.org

27. Khan SA, Taylor-Robinson SD, Carmichael PL, et al. Analysis of p53 mutations for a mutational signature in human intrahepatic cholangiocarcinoma. Int $\mathrm{J}$ Oncol 2006;28:1269-77.

28. Ferrell P, eds. MacSween's Pathology of the Liver. 5th edn. Churchill Livingstone Elsevier, 2007:761-814

29. Goodman ZD. Neoplasms of the liver. Mod Pathol 2007;20(Suppl 1):S49-60.

30. Yamasaki S. Intrahepatic cholangiocarcinoma: macroscopic type and stage classification. J Hepatobiliary Pancreat Surg 2003;10:288-91.

31. Aishima S, Kuroda Y, Nishihara Y, et al. Proposal of progression model for intrahepatic cholangiocarcinoma: clinicopathologic differences between hilar type and peripheral type. Am J Surg Pathol 2007;31:1059-67.

32. Güllüoglu MG, Ozden I, Poyanli $A$, et al. Intraductal growth-type mucin-producing peripheral cholangiocarcinoma associated with biliary papillomatosis. Ann Diagn Pathol 2007:11:34-40.
33. Bergquist A, Tribukait B, Glaumann $\mathrm{H}$, et al. Can DNA cytometry be used for evaluation of malignancy and premalignancy in bile duct strictures in primary sclerosing cholangitis? J Hepatol 2000;33:873-7.

34. Durnez A, Verslype C, Nevens F, et al. The clinicopathological and prognostic relevance of cytokeratin 7 and 19 expression in hepatocellular carcinoma. A possible progenitor cell origin. Histopathology 2006:49:138-51.

35. Sempoux C, Jibara G, Ward SC, et al. Intrahepatic cholangiocarcinoma: new insights in pathology. Semin Liver Dis 2011;31:49-60.

36. Gores GJ. Early detection and treatment of cholangiocarcinoma. Liver Transp/ 2000;6(6 Suppl 2):S30-4.

37. Patel AH, Harnois DM, Klee GG, et al. The utility of CA 19-9 in the diagnoses of cholangiocarcinoma in patients without primary sclerosing cholangitis. Am J Gastroenterol 2000;95:204-7.

38. Hultcrantz R, Olsson R, Danielsson A, et al. A 3-year prospective study on serum tumor markers used for detecting cholangiocarcinoma in patients with primary sclerosing cholangitis. J Hepatol 1999;30:669-73

39. Valle J, Wasan $\mathrm{H}$, Palmer $\mathrm{DH}$, et al: $\mathrm{ABC}-02$ Trial Investigators. Cisplatin plus gemcitabine versus gemcitabine for biliary tract cancer. $N$ Engl J Med 2010;362:1273-81.

40. Abbas G, Lindor KD. Cholangiocarcinoma in primary sclerosing cholangitis. $J$ Gastrointest Cancer 2009; 40:19-25

41. Ghazale A, Chari ST, Zhang L, et al. Immunoglobulin G4-associated cholangitis: clinical profile and response to therapy. Gastroenterology 2008; 134:706-15.

42. Kuszyk BS, Soyer P, Bluemke DA, et al. Intrahepatic cholangiocarcinoma: the role of imaging in detection and staging. Crit Rev Dian Imaging 1997;38:59-88.

43. Aljiffry M, Walsh MJ, Molinari M. Advances in diagnosis, treatment and palliation of cholangiocarcinoma: 1990-2009. World J Gastroenterol 2009:15:4240-62.

44. Charatcharoenwitthaya $\mathbf{P}$, Enders $\mathrm{FB}$, Halling $\mathrm{KC}$, et al. Utility of serum tumor markers, imaging, and biliary cytology for detecting cholangiocarcinoma in primary sclerosing cholangitis. Hepatology 2008:48:1106-17.

45. Ariff B, Lloyd CR, Khan S, et al. Imaging of liver cancers. World J Gastroenterol 2009;15:1289-300.

46. Maccioni F, Martinelli M, Al Ansari N, et al. Magnetic resonance cholangiography: past, present and future. Eur Rev Med Pharmacol Sci 2010;14:721-5

47. Ashok KS. Role of MRCP versus ERCP in bile duct cholangiocarcinoma and benign stricture. Biomed Imaging Interv J 2007;3:e12-545.

48. Vergel YB, Chilcott J, Kaltenthaler E, et al. Economic evaluation of MR cholangiopancreatography compared to diagnostic ERCP for the investigation of biliary tree obstruction. Int J Surg 2006;4:12-19.

49. Silva MA, Tekin K, Aytekin F, et al. Surgery for hilar cholangiocarcinoma; a 10 yea experience of a tertiary referral centre in the UK. Eur J Surg Oncol 2005;31:533-9.

50. Moreno Luna LE, Kipp B, Halling KC, et al. Advanced cytologic techniques for the detection of malignant pancreatobiliary strictures. Gastroenterology 2006:131:1064-72.

51. Levy MJ, Baron TH, Clayton AC, et al. Prospective evaluation of advanced molecular markers and imaging techniques in patients with indeterminate bile duct strictures. Am J Gastroenterol 2008;103:1263-73.

52. DeWitt J, Misra VL, Leblanc JK, et al. EUS-guided FNA of proximal biliary strictures after negative ERCP brush cytology results. Gastrointest Endosc 2006:64:325-33.

53. Weynand B, Deprez P. Endoscopic ultrasound guided fine needle aspiration in biliary and pancreatic diseases: pitfalls and performances. Acta Gastroenterol Belg 2004;67:294-300.

54. Kluge R, Schmidt F, Caca K, et al. Positron emission tomography with $\left[{ }^{18} \mathrm{~F}\right]$ fluor-2 deoxy-D-glucose for diagnosis and staging of bile duct cancer. Hepatology 2001:33:1029-35.

55. Kim JY, Kim MH, Lee TY, et al. Clinical role of 18F-FDG PET-CT in suspected and potentially operable cholangiocarcinoma: a prospective study compared with conventional imaging. Am J Gastroenterol 2008;103:1145-51.

56. Gonda TA, Glick MP, Sethi A, et al. Polysomy and p16 deletion by fluorescence in situ hybridization in the diagnosis of indeterminate biliary strictures. Gastrointest Endosc 2012;75:74-9.

57. Petersen BT. Cholangioscopy for special applications: primary sclerosing cholangitis, liver transplant, and selective duct access. Gastrointest Endosc Clin N Am 2009; 19:579-86.

58. Chen YK, Parsi MA, Binmoeller KF, et al. Single-operator cholangioscopy in patients requiring evaluation of bile duct disease or therapy of biliary stones (with videos). Gastrointest Endosc 2011;74:805-14.

59. Ruys AT, Busch OR, Gouma DJ, et al. Staging laparoscopy for hilar cholangiocarcinoma: is it still worthwhile? Ann Surg Oncol 2011;18:2647-53.

60. Hillen HF. Unknown primary tumours. Postgrad Med J 2000;76:690-3

61. Bergquist A, Ekbom A, Olsson R, et al. Hepatic and extrahepatic malignancies in primary sclerosing cholangitis. J Hepatol 2002;36:321-7.

62. Buckles DC, Lindor KD, Larusso NF, et al. In primary sclerosing cholangitis, gallbladder polyps are frequently malignant. Am J Gastroenterol 2002:97:1138-42.

63. Kitiyakara T, Chapman RW. Chemoprevention and screening in primary sclerosing cholangitis. Postgrad Med J 2008;84:228-37.

64. Boberg KM. Current Consensus on Management of Primary Sclerosing Cholangitis. EASL Postgraduate Course, 2011. http://www.easl.eu/liver-congress

65. Beuers U, Boberg KM, Chapman RW, et al. EASL Clinical Practice Guidelines: management of cholestatic liver diseases. European Association for the Study of the Liver. J Hepatol 2009;51:237-67. 
66. Chapman R, Fevery J, Kalloo A, et al. AASLD Practice Guidelines: diagnosis and management of primary sclerosing cholangitis. Hepatology 2010;51:660-78.

67. Sano T, Shimada K, Sakamoto Y, et al. One hundred two consecutive hepatobiliary resections for perihilar cholangiocarcinoma with zero mortality. Ann Surg 2006;244:240-7.

68. Shaib YH, Davila JA, Henderson L, et al. Endoscopic and surgical therapy for intrahepatic cholangiocarcinoma in the United States: a population-based study. J Clin Gastroenterol 2007;:41:911-17.

69. Kozarek RA. Inflammation and carcinogenesis of the biliary tract: update on endoscopic treatment. Clin Gastroenterol Hepatol 2009;7(11 Suppl): S89-94.

70. Blechacz B, Gores GJ. Cholangiocarcinoma: advances in pathogenesis, diagnosis, and treatment. Hepatology 2008;48:308-21.

71. Ustundag Y, Bayraktar Y. Cholangiocarcinoma: a compact review of the literature. World J Gastroenterol 2008;14:6458-66.

72. Ramacciato G, Nigri G, Bellagamba R, et al. Univariate and multivariate analysis of prognostic factors in the surgical treatment of hilar cholangiocarcinoma. Am Surg 2010;76:1260-8

73. Nuzzo G, Giuliante F, Ardito F, et al. Intrahepatic cholangiocarcinoma: prognostic factors after liver resection. Updates Surg 2010;62:11-19.

74. Palavecino M, Abdalla EK, Madoff DC, et al. Portal vein embolization in hilar cholangiocarcinoma. Surg Oncol Clin N Am 2009;18:257-67, viii.

75. Yi B, Xu AM, Lai EC, et al. Preoperative portal vein embolization for hilar cholangiocarcinoma: a comparative study. Hepatogastroenterology 2010;57:1341-6.

76. Sakamoto $\mathbf{Y}$, Shimada K, Nara S, et al. Risk factors for early bilirubinemia after major hepatectomy for perihilar cholangiocarcinoma with portal vein embolization. Hepatogastroenterology 2010:57:22-8.

77. Meyer CG, Penn I, James L. Liver transplantation for cholangiocarcinoma: results in 207 patients. Transplantation 2000;69:1633-7.

78. De Vreede I, Steers JL, Burch PA, et al. Prolonged disease-free survival after orthotopic liver transplantation plus adjuvant chemoirradiation for cholangiocarcinoma. Liver Transp/ 2000:6:309-16.

79. Gores GJ, Nagorney DM, Rosen CB. Cholangiocarcinoma: is transplantation an option? For whom? J Hepatol 2007;47:455-9.

80. Rosen CB, Heimbach JK, Gores GJ. Surgery for cholangiocarcinoma: the role of liver transplantation. HPB (Oxford) 2008;10:186-9.

81. Darwish MS, Kim WR, Harnois DM, et al. Efficacy of neoadjuvant chemoradiation followed by liver transplantation for perihilar cholangiocarcinoma at 12 US centers. Gastroenterology 2012;143:88-98.e3.

82. UK CRN BILCAP Trial. http://england.ukcrn.org.uk/StudyDetail.aspx?StudyID=1473

83. Nordback IH, Pitt HA, Coleman J, et al. Unresectable hilar cholangiocarcinoma: percutaneous versus operative palliation. Surgery 1994:115:597-603

84. Lammer J, Hausegger KA, Fluckiger $\mathrm{F}$, et al. Common bile duct obstruction due to malignancy: treatment with plastic versus metal stents. Radiology 1996:201:167-72.

85. Hochwald SN, Burke EC, Jarnagin WR, et al. Association of preoperative biliary stenting with increased postoperative infectious complications in proximal cholangiocarcinoma. Arch Surg 1999:134:261-6.

86. Nakeeb A, Pitt HA. The role of preoperative biliary decompression in obstructive jaundice. Hepatogastroenterology 1995;42:332-7.

87. Eckhard R, Abou-Rebyeh $\mathrm{H}$, Adler A, et al. Magnetic resonance cholangiopancreatography-guided unilateral endoscopic stent placement for Klatskin tumors. Gastrointest Endosc 2001:53:40-6.

88. Chang WH, Kortan P, Haber GB. Outcome in patients with bifurcation tumors who undergo unilateral versus bilateral hepatic duct drainage. Gastrointest Endosc 1998:47:354-62

89. De Palma GD, Galloro G, Sicialiano S, et al. Unilateral versus bilateral endoscopic hepatic duct drainage in patients with malignant hilar biliary obstruction: results of a prospective, randomized, and controlled study. Gastrointest Endosc 2001; 53:547-53

90. Jethwa $\mathbf{P}$, Breuning $E$, Bhati $C$, et al. The microbiological impact of pre-operative biliary drainage on patients undergoing hepato-biliary-pancreatic surgery. Aliment Pharmacol Ther 2007;25:1175-80.

91. Wang 0, Gurusamy KS, Lin $\mathrm{H}$, et al. Preoperative biliary drainage for obstructive jaundice. Cochrane Database Syst Rev 2008;(3):CD005444.

92. van der Gaag NA, Rauws EA, van Eijck $\mathrm{CH}$, et al. Preoperative biliary drainage for cancer of the head of the pancreas. N Engl J Med 2010;362:129-37.

93. Stern N, Sturgess R. Endoscopic therapy in the management of malignant biliary obstruction. Eur J Surg Oncol 2008;34:313-17.

94. Martin RC 2nd, Vitale GC, Reed DN, et al. Cost comparison of endoscopic stenting vs surgical treatment for unresectable cholangiocarcinoma. Surg Endosc 2002; 16:667-70.

95. Dumonceau JM, Tringali A, Blero D, et al. Biliary stenting: indications, choice of stents and results: European Society of Gastrointestinal Endoscopy (ESGE) clinical guideline. Endoscopy 2012:44:277-98.

96. Paik WH, Park YS, Hwang JH, et al. Palliative treatment with self-expandable metallic stents in patients with advanced type III or IV hilar cholangiocarcinoma: a percutaneous versus endoscopic approach. Gastrointest Endosc 2009;69:55-62.
97. Deviere J, Baize $\mathrm{M}$, de Toeuf J, et al. Long-term follow-up of patients with hilar malignant stricture treated by endoscopic internal biliary drainage. Gastrointest Endosc 1988;34:95-101.

98. Soderlund $\mathbf{C}$, Linder $\mathbf{S}$. Covered metal versus plastic stents for malignant common bile duct stenosis: a prospective, randomized, controlled trial. Gastrointest Endosc 2006:63:986-95

99. Kaassis M, Boyer J, Dumas R, et al. Plastic or metal stents for malignant stricture of the common bile duct? Results of a randomized prospective study. Gastrointest Endosc 2003:57:178-82.

100. Yeoh KG, Zimmerman MJ, Cunningham JT, et al. Comparative costs of metal versus plastic biliary stent strategies for malignant obstructive jaundice by decision analysis. Gastrointest Endosc 1999;49:466-71.

101. Moss AC, Morris E, Leyden J, et al. Do the benefits of metal stents justify the costs? A systematic review and meta-analysis of trials comparing endoscopic stents for malignant biliary obstruction. Eur J Gastroenterol Hepatol 2007; 19:1119-24

102. Raju RP, Jaganmohan SR, Ross WA, et al. Optimum palliation of inoperable hila cholangiocarcinoma: comparative assessment of the efficacy of plastic and selfexpanding metal stents. Dig Dis Sci 2011;56:1557-64.

103. Isayama $\mathbf{H}$, Komatsu $Y$, Tsujino $T$, et al. A prospective randomised study of "covered" versus "uncovered" diamond stents for the management of distal malignant biliary obstruction. Gut 2004;53:729-34.

104. Kahaleh M, Tokar J, Conaway MR, et al. Efficacy and complications of covered Wallstents in malignant distal biliary obstruction. Gastrointest Endosc 2005:61:528-33.

105. Krokidis M, Fanelli F, Orgera G, et al. Percutaneous treatment of malignant jaundice due to extrahepatic cholangiocarcinoma: covered Viabil stent versus uncovered Wallstents. Cardiovasc Intervent Radiol 2010; 33:97-106.

106. Kullman E, Frozanpor F, Söderlund C, et al. Covered versus uncovered selfexpandable nitinol stents in the palliative treatment of malignant distal biliary obstruction: results from a randomized, multicenter study. Gastrointest Endosc 2010:72:915-23.

107. Ortner ME, Caca K, Berr F, et al. Successful photodynamic therapy for nonresectable cholangiocarcinoma: a randomized prospective study. Gastroenterology 2003;125:1355-63

108. Pereira S, Hughes SK, Roughton M, et al. Photostent-02; Porfimer Sodium photodynamic therapy plus stenting versus stenting alone in patients with advanced or metastatic cholangiocarcinomas and other biliary tract tumours: a multicentre, randomised phase III trial. ESMO 2010 (Abstract No. 8020). http://www.postersubmission.com/search/select/18

109. Shinchi H, Takao S, Nishida $\mathrm{H}$, et al. Length and quality of survival following external beam radiotherapy combined with expandable metallic stent for unresectable hilar cholangiocarcinoma. J Surg Oncol 2000:75:89-94.

110. Shinohara ET, Mitra N, Guo M, et al. Radiation therapy is associated with improved survival in the adjuvant and definitive treatment of intrahepatic cholangiocarcinoma. Int J Radiat Oncol Biol Phys 2008; 72:1495-501.

111. Shinohara ET, Mitra N, Guo M, et al. Radiotherapy is associated with improved survival in adjuvant and palliative treatment of extrahepatic cholangiocarcinomas. Int J Radiat Oncol Biol Phys 2009;74:1191-8.

112. Válek V, Kysela P, Kala Z, et al. Brachytherapy and percutaneous stenting in the treatment of cholangiocarcinoma: a prospective randomised study. Eur J Radiol 2007:62:175-9.

113. Valle JW, Wasan $\mathrm{H}$, Johnson $\mathrm{P}$, et al. Gemcitabine alone or in combination with cisplatin in patients with advanced or metastatic cholangiocarcinomas or other biliary tract tumours: a multicentre randomised phase II study: the UK ABC-01 Study. Br J Cancer 2009;101:621-7.

114. Furuse J, Okusaka T, Bridgewater $\mathrm{J}$, et al. Lessons from the comparison of two randomized clinical trials using gemcitabine and cisplatin for advanced biliary tract cancer. Crit Rev Oncol Hematol 2011:80:31-9.

115. Roth JA, Carlson JJ. Cost-effectiveness of gemcitabine + cisplatin vs. gemcitabine monotherapy in advanced biliary tract cancer. J Gastrointest Cancer 2012:43:215-23.

116. Takada T, Amano $\mathrm{H}$, Yasuda $\mathrm{H}$, et al. Is post-operative adjuvant chemotherapy useful for gallbladder carcinoma? A phase III multicenter prospective randomized controlled trial in patients with resected pancreaticobiliary carcinoma. Cancer 2002;95:1685-95

117. Park SY, Kim JH, Yoon HJ et al. Transarterial chemoembolization versus supportive therapy in the palliative treatment of unresectable intrahepatic cholangiocarcinoma. Clin Radiol 2011;66:322-8.

118. Wu ZF, Zhang HB, Yang N, et al. Postoperative adjuvant transcatheter arteria chemoembolisation improves survival of intrahepatic cholangiocarcinoma patients with poor prognostic factors: results of a large monocentric series. Eur J Surg Oncol 2012;38:602-10.

119. Kuhlmann JB, Euringer W, Spangenberg HC, et al. Treatment of unresectable cholangiocarcinoma: conventional transarterial chemoembolization compared with drug eluting bead-transarterial chemoembolization and systemic chemotherapy. Eur J Gastroenterol Hepatol 2012;24:437-43.

120. Xu HX, Wang Y, Lu MD, et al. Percutaneous ultrasound-guided thermal ablation for intrahepatic cholangiocarcinoma. Br J Radiol 2012;85:1078-84. 
121. Fu Y, Yang W, Wu W, et al. Radiofrequency ablation in the management of unresectable intrahepatic cholangiocarcinoma. J Vasc Interv Radiol 2012;23:642-9.

122. Giorgio A, Calisti G, DE Stefano G, et al. Radiofrequency ablation for intrahepatic cholangiocarcinoma: retrospective analysis of a single centre experience. Anticancer Res 2011;31:4575-80.

123. Haidu M, Dobrozemsky G, Schullian $\mathrm{P}$, et al. Stereotactic radiofrequency ablation of unresectable intrahepatic cholangiocarcinomas: a retrospective study.
Cardiovasc Intervent Radiol. Published Online First: 18 October 2011. doi: 10.1007/ s00270-011-0288-6

124. Kim JH, Won HJ, Shin YM, et al. Radiofrequency ablation for the treatment of primary intrahepatic cholangiocarcinoma. AJR Am J Roentgenol 2011;196:W205-9.

125. Hoffmann RT, Paprottka PM, Schön A, et al. Transarterial hepatic yttrium-90 radioembolization in patients with unresectable intrahepatic cholangiocarcinoma: factors associated with prolonged survival. Cardiovasc Intervent Radiol 2012;35:105-16. 